observed, and implies that there is no significant dependence of valence electron 'slip' upon the angular momentum of the molecule.

From the Zeeman splitting of the $K=1$ com. ponent of the $J=1 \rightarrow 2$ doublet in the spectrum of $\mathrm{CH}_{3} \mathrm{CCH}$, we have obtained $g_{z z}=0 \cdot 30 \pm 0 \cdot 02$, in close agreement with the values found by Cox and Gordy ${ }^{4}$ from the $J=2 \rightarrow 3$ and $J=3 \rightarrow 4$ transitions, namely, $g_{z z}=0.298 \pm 0.006$. In agreement with Cox and Gordy, we find no observable splitting of the $K=0$ component, that is, $g_{x x} \approx 0$.

R. W. R. HoISINGTON

C. KELLNER

M. J. Pentz

Imperial College of Science and Technology, South Kensington, London, S.W.7.

${ }^{1}$ Jen, C. K., Phys. Rev., 74, 1396 (1948); 76, 1494 (1949).

2 Nat. Bur. Stand. Cire. No. 518.

${ }^{3}$ Eshbach, J. R., and Strandberg, M. W. P., Phys. Rev., 85, 24 (1952).

4 Cox, J. T., and Gordy, W., Phys. Rev., 101, 1298 (1956).

\section{Combustion of Methane}

IT is known that the most reactive mixture of methane and oxygen is $2 \mathrm{CH}_{4}+\mathrm{O}_{2}$, the most easily detonated $\mathrm{CH}_{4}+\mathrm{O}_{2}$ and the most inflammable $\mathrm{CH}_{4}+2 \mathrm{O}_{2}$. Methane is not unique in this respect because, as Coward and Payman ${ }^{1}$ have pointed out, the most reactive mixtures of each of the simple paraffin hydrocarbons with oxygen are those containing hydrocarbon and oxygen in the molecular proportion 2:I; yet none of these mixtures can propagate flame at normal temperature and pressure. An interpretation of these curious facts may be suggested on the following lines.

The 2:1 ratio of methane to oxygen in the most reactive mixture implies that the determining step in the slow combustion of methane involves two molecules of methane and one of oxygen. (The word step is used in the thermodynamic, not the kinetic, sense. That is, we are concerned with equilibrium states, not the route from one to the other.) The slowness of the reaction is probably indicative of the low frequency of three-body collisions involving specifically two molecules of methane and one of oxygen. Its easy initiation, on the other hand, argues that relatively little energy is needed to disturb the equilibrium of this tri-molecular grouping and enable it to pass into the next equilibrium state. The simplest rearrangement would appear to be the splitting of the oxygen molecule, which must always happen, and the assimilation of one oxygen atom by each methane molecule. Thus,

$$
\mathrm{CH}_{4}+(\mathrm{O}+\mathrm{O})+\mathrm{CH}_{4} \rightarrow 2 \mathrm{CH}_{8} \mathrm{OH}+78 \mathrm{k} . \mathrm{cal} \text {. }
$$

This initial formation of methanol fits in with Bone's ${ }^{2}$ scheme for the slow oxidation of methane.

The fact that the equimolecular mixture of methane and oxygen is the most readily detonated suggests that the initial step here is a two-body collision process involving one molecule of each kind. The products of the detonation reaction ${ }^{2}$ are $\mathrm{CO}+\mathrm{H}_{2}+\mathrm{H}_{2} \mathrm{O}$ and so it may be inferred that the determining step in the detonation of methane-oxygen mixtures can be reprisented thus :

$$
\begin{aligned}
\mathrm{CH}_{4}+\mathrm{O}_{2} & \rightarrow\left(\mathrm{C}+\mathrm{H}_{2}+\mathrm{H}_{2}\right)+(\mathrm{O}+\mathrm{O}) \\
& \rightarrow \mathrm{CO}+\mathrm{H}_{2}+\mathrm{H}_{2} \mathrm{O}+77 \mathrm{k} . \text { cal. }
\end{aligned}
$$

Hence the methane molecule also divides and, since three new molecules are formed, it must divide into three. This implies that much more energy per mole is required to trigger detonation than slow com. bustion.

The optimum proportions in the case of deflagration seem at first sight to suggest a three-body collision process involving one molecule of methane and two of oxygen; but this is statistically improbable in view of the speed of this reaction. The alternative would appear to be two successive bi-molecular encounters involving first one oxygen molecule and then the other. The first event, however, must be distinguished from detonation and, since deflagration is easier to initiate, it is reasonable to suppose that, in this case, the methane molecule divides into two instead of three. In other words, the methane molecule is stripped of one hydrogen pair instead of two. This may be represented :

$$
\begin{aligned}
\mathrm{CH}_{4}+\mathrm{O}_{2} & \rightarrow\left(\mathrm{CH}_{2}+\mathrm{H}_{2}\right)+(\mathrm{O}+\mathrm{O})+78 \text { k.cal. } \\
& \rightarrow \mathrm{CH}_{2} \mathrm{O}+\mathrm{H}_{2} \mathrm{O}+\mathrm{O}_{2}+135 \mathrm{k} . c a l .
\end{aligned}
$$

The second stage of the reaction will, of course, benefit from the energy released in the first and may require no other help to initiate it, in which case the second stage follows spontaneously. Thus the activation energy of the whole process may correspond to that of the first stage whereas the total energy released is the sum of the two, namely, 213 kcal. per mole of methane.

The interesting point emerges that the energy released in detonation may represent only part of the total energy available and may in fact be much less than that generated by deflagration. The violence of the detonation process thus appears to be due more to the speed of the reaction than to the amount of energy released, and this depends on the statistical frequency of encounters between the appropriate species. This probably explains why the maximum detonation velocity in mixtures of methane and oxygen occurs not in the stoichiometric but in the equimolecular mixture.

Research Department,

I.C.I. (Nobel Division),

Stevenston,

Ayrshire.

July 20.

'Coward, H. F., and Payman, W., Chem. Rev., 21, 539 (1937).

'Bone, W. A., and Townend, D. T. A., "Flame and Combustion in Gases" (Longman, 1927).

\section{Use of Irradiated Polymers as Initiators of Polymerizations}

IT has been demonstrated by physical methods ${ }^{1}$ that in some polymers free radicals are formed during exposure to high-energy radiations, and that in some cases they can survive for long periods. These radicals can also be detected by chemical methods, and under suitable conditions they can be used for initiating the polymerization of typical monomers to give graft co-polymers ${ }^{2}$. In the preliminary work described here the formation of graft co-polymers has been detected by using a monomer labelled with carbon-14; by this means it has been possible to determine accurately very small weights of grafted material. 